\title{
Investigation of the process of strong acoustic signal propagation in a layered environment of ice-water-bottom
}

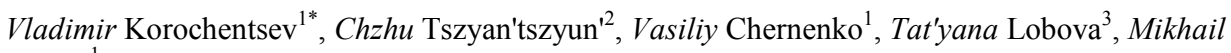 \\ Gubko $^{1}$ \\ ${ }^{1}$ FEFU, Engineering school, Department of instrumentation, Russia \\ ${ }^{2} \mathrm{HIU}$, Institute of hydroacoustics, China \\ ${ }^{3}$ MSUN, Electromechanical faculty, Department of Physics, Russia
}

\begin{abstract}
A mathematical model was developed to calculate acoustic wave in a shallow sea under an ice layer for low frequency signals of 40$150 \mathrm{~Hz}$. An experimental unit was developed by the authors on the basis of a low-frequency piston-type electrodynamic radiator which is capable of making experiments in layered environment. The experiments show satisfactory agreement with theoretical investigations. The peculiarities of wave propagation at water-ice boundary are under investigation. The developed models may be applied for new engineering systems for earthquake forecast when installing receiving systems in an ice layer.
\end{abstract}

\section{Introduction}

Development of new communication means for shelf zone investigation, earthquake predictions require effective techniques to calculate wave processes in a shallow sea. A great number of papers $[1,2,3,4]$ is devoted to the development of the theory for field analysis. However, current methods are cumbersome and need significant time investments for engineering calculations. The main mathematical problem of analysis of a filed in a shallow sea is the lack of boundary condition uniformity in different directions of space. In the paper, we suggest to apply «directed» Green's functions to solve the problems of calculation of the field in a space inhomogeneous in angular coordinates [5, 6]. In the proposed algorithm, an inhomogeneous region is divided into homogeneous sections bounded by simple plane surfaces. The whole closed volume is considered by summing up the solutions of separate sections. The aim of the paper is to investigate experimentally the mathematical model of strong acoustic signal propagation in a shallow sea covered by ice.

\footnotetext{
*Corresponding author: ga i uzt@mail.ru
} 


\section{Mathematical model}

The aim of the paper is theoretical and experimental investigations of the process of strong acoustic signal propagation in layered environment, in a closed volume (shallow sea), bounded by sea bottom and ice cover, for practical application in real conditions.

We choose Helmholtz equation as a mathematical model

$$
\Delta \mathrm{P}+\left(\omega / \mathrm{c}_{\mathrm{n}}\right)^{2} \mathrm{P}=\delta\left(\theta, \theta_{0}, \mathrm{r}, \mathrm{r}_{0}\right),
$$

where

$\mathrm{P}$ is the pressure in an elastic wave;

$\mathrm{c}_{\mathrm{n}}$ is the phase propagation velocity in ice, water and ground;

$\omega$ is the circular frequency $2 \pi / T$, where $\mathrm{T}$ is the period of harmonic oscillation;

$\delta\left(\theta, \theta_{0}, \mathrm{r}, \mathrm{r}_{0}\right)$ is Dirac delta function depending on distance $\mathrm{r}$ and angle $\theta$.

Boundary values in ice, water and ground layer are chosen from real characteristics of shallow sea.

Such a problem can be taken as the initial one when calculating hydroacoustic radiator placed in an ocean under an ice cover [5,6]. Assume that acoustic characteristics (density and phase velocity) of ice, water, air and radiator elements coordinates are known. Radiator field is determined by pressure in the ocean.

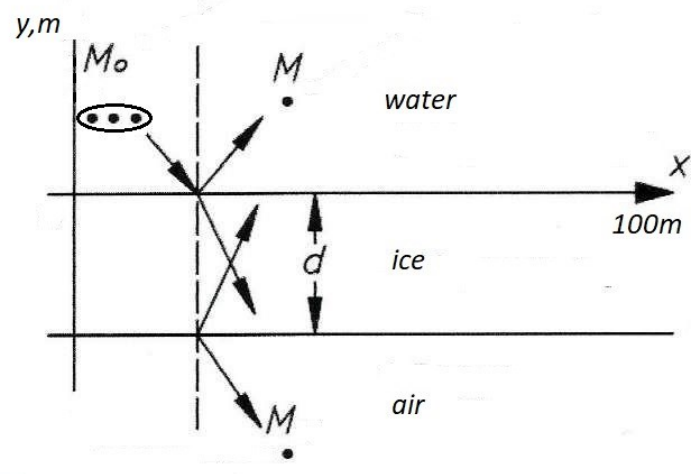

Fig. 1. Geometry of radiator analysis problem.

The major difficulty when solving such a problem is the impossibility to divide the variables in Helmholtz equation and to satisfy the boundary conditions. It is convenient to solve this equation by the method of Green directed functions [1].

The calculation algorithm is as follows.

$$
\begin{aligned}
& \mathrm{F}_{0}\left(\mathrm{U}_{0}\right)=\mid \begin{array}{c}
1 \text { if } \mathrm{U}_{0 \min } \leq \mathrm{U}_{0}<\mathrm{U}_{0 \max }, \\
0 \text { otherwise }
\end{array} \\
& \mathrm{Z}_{0}\left(\mathrm{U}_{1}\right)=\rho_{00} \mathrm{c}_{00} / \cos \left[\operatorname{asin}\left(\frac{\mathrm{U}_{1}}{\mathrm{k}_{0}}\right)\right]
\end{aligned}
$$


$\frac{+\left[Z_{2}(x)-Z_{1}(x)\right]\left[Z_{1}(x)+Z_{0}(x)\right] e^{\left[i\left(\sqrt{k_{2}^{2}-\left\{k_{2} \sin \left[x\left(2 \frac{\pi}{360}\right)\right]^{2}\right\} d}\right)\right]}}{+\left[Z_{2}(x)-Z_{1}(x)\right]\left[Z_{1}(x)-Z_{0}(x)\right] e^{\left[i\left(\sqrt{k_{2}^{2}-\left\{k_{2} \sin \left[x\left(2 \frac{\pi}{360}\right)\right]^{2}\right\} d}\right)\right]}}$

$$
\mathrm{V}(\mathrm{x})=\frac{\left[\mathrm{Z}_{2}(\mathrm{x})+\mathrm{Z}_{1}(\mathrm{x})\right]\left[\mathrm{Z}_{1}(\mathrm{x})-\mathrm{Z}_{0}(\mathrm{x})\right] \mathrm{e}^{\left(-\mathrm{i}\left\{\mathrm{k}_{2} \sin \left[\mathrm{x}\left(2 \frac{\pi}{360}\right) \mathrm{d}\right]\right\}\right)_{+}}}{\left[\mathrm{Z}_{2}(\mathrm{x})+\mathrm{Z}_{1}(\mathrm{x})\right]\left[\mathrm{Z}_{1}(\mathrm{x})+\mathrm{Z}_{0}(\mathrm{x})\right] \mathrm{e}^{\left(-\mathrm{i}\left\{\mathrm{k}_{2} \sin \left[\mathrm{x}\left(2 \frac{\pi}{360}\right) \mathrm{d}\right]\right\}\right)_{+}}}
$$

$$
\begin{aligned}
& \mathrm{P}_{12}(\mathrm{x})=\int_{\mathrm{U}_{0 \min }}^{\mathrm{U}_{0 \max }} \frac{\mathrm{i}}{\frac{2 \pi}{\mathrm{F}} \mathrm{F}_{0}\left(\mathrm{U}_{0}\right) \mathrm{P}} \operatorname{\sqrt {\mathrm {k}_{2}^{2}-\mathrm {U}_{0}^{2}}} \exp \left(\mathrm{i}\left\{\left[\left(\mathrm{x}-\mathrm{x}_{1}\right) \sqrt{\mathrm{k}_{2}^{2}-\mathrm{U}_{0}^{2}}\right]+\left(\mathrm{y}(\mathrm{x})-\mathrm{y}_{0}\right) \mathrm{U}_{0}\right\}\right) \mathrm{dU}_{0}+ \\
& +\int_{\mathrm{U}_{0 \min }}^{\mathrm{U}_{0 \max }} \mathrm{V}(\mathrm{x})\left[\frac{\frac{\mathrm{i}}{2 \pi} \mathrm{F}_{0}\left(\mathrm{U}_{0}\right) \mathrm{P}}{\sqrt{\mathrm{k}_{2}^{2}-\mathrm{U}_{0}^{2}}} \exp \left(\mathrm{i}\left\{\left[\left(\mathrm{x}-\mathrm{x}_{1}\right) \sqrt{\mathrm{k}_{2}^{2}-\mathrm{U}_{0}^{2}}\right]+\left(\mathrm{y}(\mathrm{x})-\mathrm{y}_{0}\right) \mathrm{U}_{0}\right\}\right)\right] \mathrm{dU}_{0},
\end{aligned}
$$

$$
\left|\mathrm{P}_{12}(\mathrm{x})\right|=\sqrt{\operatorname{Re}\left[\mathrm{P}_{12}(\mathrm{x})\right]^{2}+\operatorname{Im}\left[\mathrm{P}_{12}(\mathrm{x})\right]^{2}}
$$

$$
\left|\mathrm{P}_{123}(\mathrm{x})\right|=\sqrt{\left\{\operatorname{Re}\left[\mathrm{P}_{12}(\mathrm{x})\right]+\operatorname{Re}\left[\mathrm{P}_{22}(\mathrm{x})\right]+\operatorname{Re}\left[\mathrm{P}_{33}(\mathrm{x})\right]\right\}^{2}+\left\{\operatorname{Im}\left[\mathrm{P}_{12}(\mathrm{x})\right]+\operatorname{Im}\left[\mathrm{P}_{22}(\mathrm{x})\right]+\operatorname{Im}\left[\mathrm{P}_{33}(\mathrm{x})\right]\right\}^{2}}
$$

where

$\rho$ is the densities of respective environments of space;

$\mathrm{y}_{0}, \mathrm{x}_{1}, \mathrm{x}_{2}, \mathrm{x}_{3}$ are the elastic wave source coordinates;

$\mathrm{Z}$ is the impedance;

$\mathrm{x}, \mathrm{y}(\mathrm{x})$ are the receiver coordinates;

$\mathrm{d}$ is the ice layer thickness;

$\mathrm{F}_{0}\left(\mathrm{U}_{0}\right)$ is the function characterizing Green directed function properties;

$\mathrm{V}(\mathrm{x})$ is the reflection coefficient;

$\mathrm{P}_{12}, \mathrm{P}_{22}, \mathrm{P}_{33}$ is the pressure on respective receivers $\mathrm{x}_{1}, \mathrm{x}_{2}, \mathrm{x}_{3}$;

$\mathrm{P}_{123}$ is the total from the three receivers.

Applying the algorithms, we calculate elastic wave parameters depending on space coordinates $\theta$ and $r$.

\section{Results of theoretical calculations.}


A mathematical model of three-element antenna array was taken as a receiver:

- Frequency is $\mathrm{f}=1500 \mathrm{~Hz}$;

- Wavelength is $\lambda=1$ meter;

- Ice thickness is $\mathrm{d}=0,4$ meter;

- Ultrasound wave propagation velocity in the water is $1500 \mathrm{~m} / \mathrm{s}$;

- Ultrasound wave propagation velocity in the air $331 \mathrm{~m} / \mathrm{s}$;

- Ultrasound wave propagation velocity in the ice $3980 \mathrm{~m} / \mathrm{s}$;

- Distance between the radiator and the hydrophone is $100 \mathrm{~m}$.

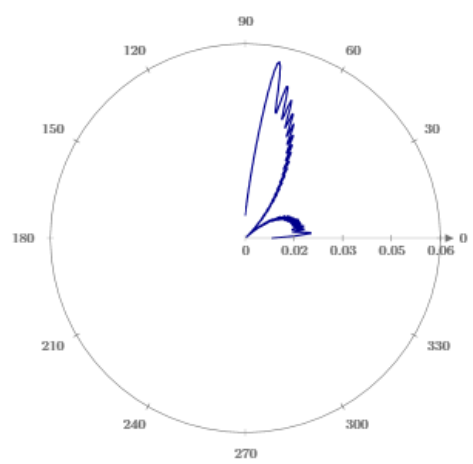

Fig.2. Directivity graph for antenna array of three elements located in free space at the distances of 10 $\mathrm{m}, 10.5 \mathrm{~m}$ and $11 \mathrm{~m}$.

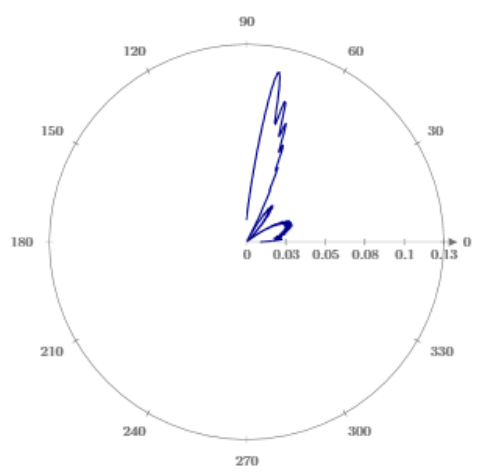

Fig.3. Directivity graph for antenna array of three elements located at the distances of $10 \mathrm{~m}, 10.5 \mathrm{~m}$ and $11 \mathrm{~m}$ taking into account reflection coefficient from ice.

\section{Experimental part.}

To check the calculation results experimentally, we developed a low-frequency pneumatic radiator of strong acoustic signals. Fig. 4 show the physical configuration of the radiator. 


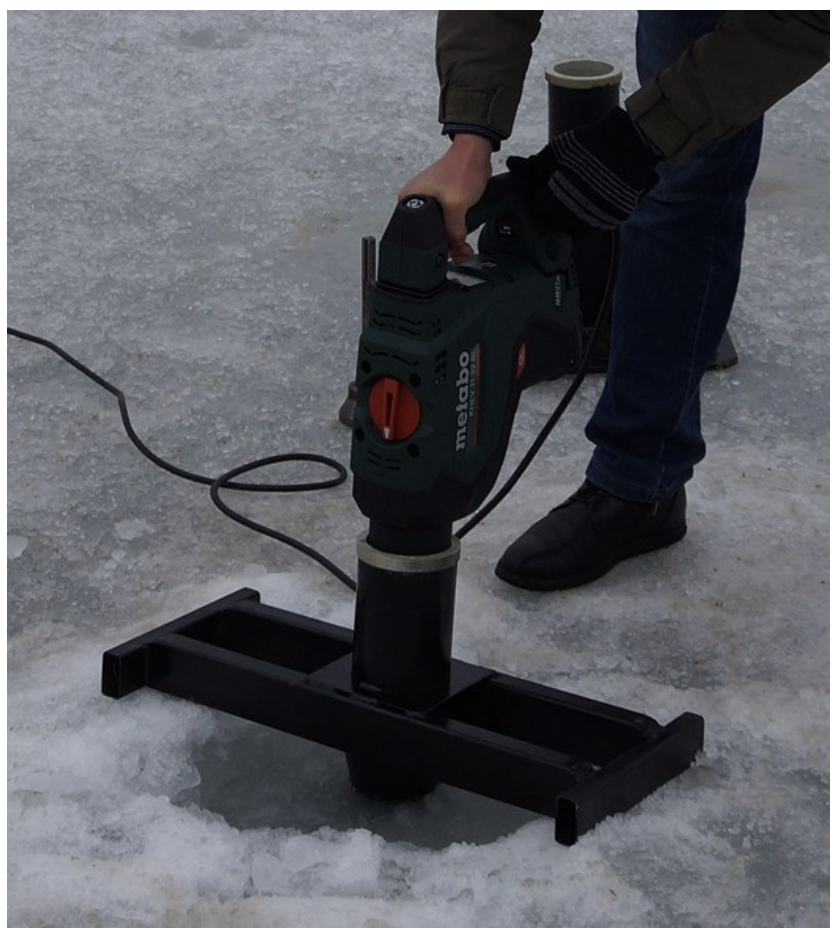

Fig. 4. Under-ice part of the radiator.

Main characteristics of the radiator:

- Work is $20 \mathrm{~J}$.

- Frequency range is from $40 \mathrm{~Hz}$ to $1000 \mathrm{~Hz}$.

\section{Results.}

The investigations were carried out in winter time during the following conditions: air temperature was minus $8^{\circ} \mathrm{C}$; wind velocity was not more than $5 \mathrm{~m} / \mathrm{s}$; ice thickness was 0.3 $0.4 \mathrm{~m}$; water temperature was $1^{\circ} \mathrm{C}$; radiator submergence depth was $2 \mathrm{~m}$; that for the hydrophone was $1 \mathrm{~m}$; distance between the radiator and the hydrophone was $100 \mathrm{~m}$; depth in the measurement area was $8 \mathrm{~m}$; bottom was composed of sand, stones, water inhabiting plants.

A pneumatic radiator illustrated in Fig. 4 was used in the experiment.

Signals are received by a directed hydrophone. Hydrophone is a piezoceramic spherical one with $\varnothing 50 \mathrm{~mm}$. Hydrophone sensitivity is within the range of $20-2000 \mathrm{~Hz}-180 \mu \mathrm{V} / \mathrm{Pa}$ $\pm 20 \%$. Capacitance together with the cable of $6 \mathrm{~m}$ is $34 \mathrm{nF} \pm 20 \%$.

As a hydrophone amplifier we used a voltage amplifier with gain factor $\mathrm{Gf}=200$, input impedance $\mathrm{RBX}=10 \mathrm{M} \Omega$ and a pass band at the level of $-3 \mathrm{~dB} \Delta \mathrm{f}=2-4000 \mathrm{~Hz}$.

A multifunctional unit myDAQ (National Instruments) connected to a laptop was used as a recording unit for the signals received by the hydrophone. The signal sampling frequency was $10 \mathrm{kHz}, \mathrm{ADC}$ capacity was 16 binary digits. In order to protect from the air temperature change effect, the hydrophone amplifier, multifunctional unit myDAQ and the laptop were placed inside a building, where the temperature was within $15 \pm 2{ }^{\circ} \mathrm{C}$. Specialized software in LabView environment was used for signal recording and further analysis. 
Fig. 5 shows the oscillograms of signals recorded at the distance of $100 \mathrm{~m}$ from the radiator.

Dependence of pressure change in water under an ice cover, measured by the developed construction, agrees with the calculated data. The error is within $30 \%$.

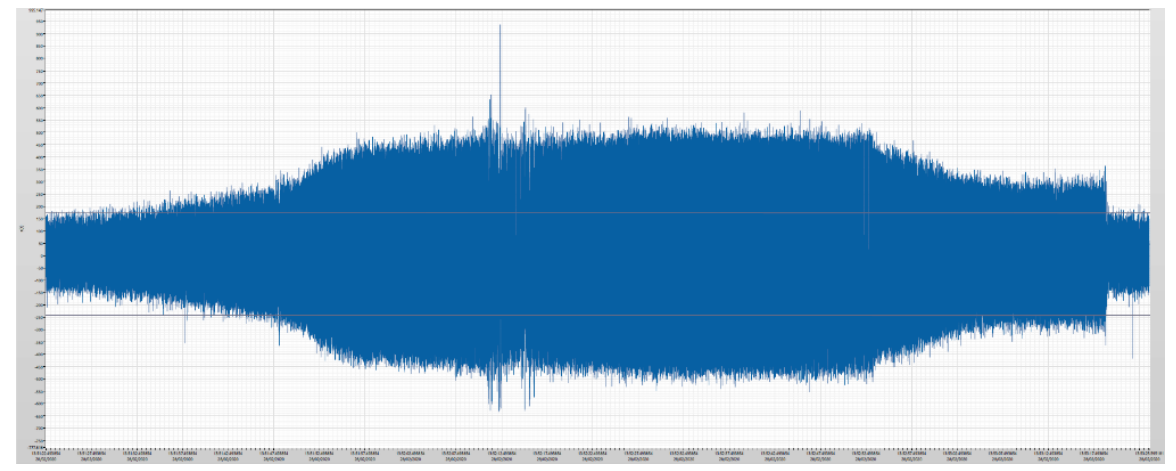

Fig 5. Oscillogram of periodic sequence of signals recorded at the distance of $100 \mathrm{~m}$ from the radiator within the time interval from 13:51:22.5 to 13:53:23.6 of local time. Horizontal axis is local time, vertical axis is acoustic pressure in PA.

\section{Discussion.}

Comparison of the parameters of hydroacoustic signals from the pneumatic radiator with the parameters of acoustic waves from real earthquakes allows us to make the conclusion on the possibility and the necessity of application of the proposed radiator and the mathematical model to investigate elastic wave propagation in water environments covered with ice in the range of several $\mathrm{kHz}$.

\section{Conclusions.}

The theory and the experimental unit described in the paper make it possible to model strong signal propagation in a shallow sea covered with ice.

The obtained results allow us to model any processes including the model of wave propagation from underwater earthquake source.

This work was supported by the grants from the Ministry of Science and Higher Education of the Russian Federation (Grant No.0657-2020-0003)

\section{References}

1. Korochentsev V.I. Volnovye zadachi teorii napravlennykh i fokusiruyushchikh antenn [Wave problems of the theory of directed and focused antennas]. Moscow, Dal'nauka, Vladivostok, 1998. 192 p. (in Russian)

2. Korochentsev V.I. Raschet gidroakusticheskikh antenn v kline s impedansnymi stenkami metodami sinteza i analiza [The calculation of the hydroacoustic antennas in a wedge with impedance walls methods of synthesis and analysis], Sovremennoe sostoyanie i perspektivy razvitiya teorii i prikladnykh voprosov gidroakustiki (k 300 letiyu Rossiyskogo flota) [Modern state and prospects of development of the theory and applied questions hydroacoustics (to the 300 anniversary of Russian fleet)]. Vladivostok, 1996. (in Russian) 
3. Lobova T.Zh., Syuan' Lin'lin', Korochentsev V.I. Grishchenko V.V. Morskie intellektual'nye tekhnologii [Marine intellectual technologies]. No. 1 (43) V.3 2019 pp. 139-144. ISSN: 2073-7173 eISSN: 2588-0233 (in Russian)

4. Korochentsev V., Lobova T., Soshina N., Yin J., Viland A. E3S WEB of conferences. 2019Г. с 02013.

5. Liu S.-X., Li Z.-L. Wuli Xuebao. 2017. T. 66. № 23. C. 234301.

6. Zaslavsky Y., Kerzhakov B., Kulinich V. 17th International Congress on Sound and Vibration 2010, ICSV 2010. 2010. C. 3006-3012. 